\title{
Theory and Practice of Chinese-English Bilingual Teaching in Circuit Course
}

\author{
Xiao Chen \\ Department of Electronic Information Engineering \\ Nanjing University of Information Science and Technology \\ Nanjing 210044, China \\ Tel: 86-25-5873-1196Ｅ-mail: rainofsun@netease.com
}

The research is supported by the Teaching Research and Reform Program of Nanjing University of Information Science and Technology, China(No. 07JY0107). (Sponsoring information)

\begin{abstract}
The Chinese-English bilingual teaching in the circuit course is an important approach to foster innovational talents for the electronic industry in the new century. In this article, we analyze the background, applicability and feasibility of bilingual teaching in the course of circuit and the difficulties facing in the process of implementation. We explore various approaches and methods to overcome these difficulties and obtain better effects from many aspects such as teaching materials, teachers, teaching method and students. Taking the teaching contents of the first chapter in the course of circuit as an example, we adopt new Chinese-English bilingual teaching system and modes to make students grasp the basic theory and method of circuit, foster students' English thinking abilities, combine the theoretic teaching of scientific and technologic English and the theoretic teaching of circuit, and enhance students' international competitive consciousness and international competitive ability.
\end{abstract}

Keywords: Bilingual teaching, Bilingual teaching material, Bilingual teachers, Circuit

\section{Introduction}

With the development of economic globalization, the communication among different cultures is continually deepened and the development trend of educational internationalization occurs. The application of high and new technology and the development of long-distance education bring intensive concussion to the higher education of China, and that largely improves the research and practice about education policy, teaching method and course offering in China. To adapt social demand for the talent cultivation in higher colleges and universities, we need continually enhancing the teaching quality of the undergraduate education. In 2001, China Ministry of Education started the "Bilingual Teaching Course Reform Plan" to improve the work of bilingual teaching reform construction.

As the electric professional basic course, the circuit course has strongly theoretic and scientific practice. The development of circuit course bilingual teaching could help students to gradually realize the communication between professional knowledge learning and technology by English, enhance their application ability of foreign language, and enhance their international competitive consciousness and international competitive capability.

\section{Background of circuit bilingual teaching}

\subsection{Demands of new talents}

The most intensive competition in the world is not in the industry and the science and technology, but in the talents. With continual development of China reform and opening, the communication among China and other countries is rapidly enlarged and embedded in various domains, and the bilingual talents who are accomplished in not only Chinese and Chinese culture but also foreign languages (English) and foreign cultures certainly be the important talents to help China participate in the international competition for China. It has become into the hotspot to cultivate reading ability, computation ability, writing ability, computer information disposal and utilization ability and modern entertainment ability by the form and means of bilingual teaching for modern talents.

2.2 Demands of modern education concept and quality education

The essential of language is tool, but human being and the society are advancing, and foreign language has been 
changed from a sort of tool to a sort of idea or a sort of repository. As viewed from learners' cognition, language is the tool to think and understand the world for human being, and to grasp a sort of language is to grasp a sort of method and habit to observe and understand the world, and to study another language means to study another method and habit to observe and understand the world. The bilingual school and the bilingual teaching are the new bright point occurring in the present experiment of English teaching reform.

\subsection{Demands of present internet network information technology}

The modern information technology represented by modern computer technology and Internet is changing human survival mode and study mode by the egregious speed, and the information technology has constructed the information-based environment, improved the efficiency of study and life, and created various new study mode and living mode with high level and high efficiency. The contriver and developer of information technology are English countries such as US, so if we want to do a job with skill and ease in the information communication and thinking, the use of English is very important. The main reason why India could be the big country of software development is that it uses English as the official language. If China wants to participate in the world information competition, we must utilize the network public language to implement communication and cooperation.

\subsection{Demands of scientific and technical economy}

In the present world, the competitive focus of comprehensive national strength rests with high and new technology, which has become into the key to maintain national dominion and economic safety. China is comprehensively implementing the strategy of invigorating the country through science and largely advancing the innovation of science and technology. To realize the innovation of science and technology, the key factor is innovational talents who must acquire and exactly research the late data. To do that, English is necessary, because the main cradle of new science and technology is in English country. In addition, the science and technology of China should participate in the global top competition, and we must use the common language to make the world notice and understand Chinese new invention and new result, and English is the only selection.

\section{Key factors to the success of circuit bilingual teaching}

\subsection{Teachers}

The key factor of bilingual teaching is teachers. The bilingual teaching has been implemented for a long time, and many schools in various areas are participating in the practice, but the effect is not obvious because the teachers with bilingual teaching ability are deficient. English teachers are easy to regard subject teaching as language teaching, but subject teachers would always induce the difficulty in the communication between teacher and students because of their superficial English base. Only topping bilingual teachers can foster excellent bilingual students and bilingual talents. Only after the problem of the total teachers is solved, the development of bilingual teaching would obtain essential advance and form certain scale.

\subsection{Teaching materials}

Nowadays, in the early stage of bilingual teaching, quite part colleges directly introduce original edition English teaching materials, and with the continual development of bilingual teaching, some colleges have begun to compile teaching materials themselves. The original edition teaching materials construct the environment to comprehensively touch English for students. The content of original edition teaching materials embodies the progress of the theory, and makes for studying advanced theoretic knowledge and late development trends of practice. But some problems such as large length, expensive charge and deviating national situation exist in original edition English teaching materials, which would influence the teaching effect. Therefore, we should compile the teaching materials according with the demand of domestic bilingual teaching.

\subsection{Teaching method}

Teachers can utilize flexible teaching method to compensate teachers' deficient qualities. For example, teachers can adopt many assistant measures such as practicality, picture, PPT and video, and many teaching methods such as situational teaching and activity teaching, and posture languages such as expression and action to help students understand the learning content and relax learners' stress of language thinking. In the bidirectional information communication between teaching and studying, teachers should continually inspire students' delighted emotional experiences and make students produce profound study interests.

\subsection{Students}

As the main body of learning, students' mental preparations are very important to influence the bilingual teaching. Theoretically speaking, students' basic preparation of foreign language should be sufficient. After students pass the learning of college public foreign language lesson and professional foreign language lesson, they have grasped certain basic knowledge. Someone may not prepare for the mental bilingual learning, and someone hadn't accomplished former learning of the college publish foreign language lesson and the professional foreign language lesson very well. Students' 
attitudes to bilingual teaching influence the effect of bilingual teaching.

\section{Problems faced by bilingual teaching in circuit course}

\subsection{Relationships between language teaching and subject teaching}

In the process of bilingual teaching, the learning effect of profession course should not be influenced because of the use of bilingual teaching mode. The arrangement of teaching process should persist in the premise that student could better understand professional knowledge. Under the premise, we can teach simple content and professional glossary by foreign language. And to profound professional theoretic knowledge, we can particularly explain by Chinese, and we should not blindly pursue the use quality of foreign language. The classroom teaching should give priority to grasp professional knowledge, but not learn foreign language.

\subsection{Teaching management mechanism}

In the management process of teaching administration department, we should not only encourage to implement bilingual teaching for the course with necessary condition, but also ensure the teaching quality and level of bilingual teaching through scientific management measure to make bilingual teaching develop normally and favorably. For example, for the hour arrangement, aiming at same teaching task, the bilingual teaching needs more hours to accomplish the task than general teaching, because it is narrated by English and Chinese together. If we don't add hours, we will not accomplish the teaching task in the next term, or else, the teaching effect is not good because of rapid schedule.

\subsection{Reform of course and teaching materials}

The reform of teaching material is the difficult to implement bilingual teaching at present. The compilation of English teaching material basically takes the training of the English knowledge structure and lingual ability as the major idea, and there are few English teaching materials of subject, and to really implement bilingual teaching. We must compile English teaching materials of various subjects, and it is a complex system engineering which should not only require familiar English and scientific knowledge system, but also arrange training of English hearing and reading skills and emphasize the thinking property and novelty property of the subject.

\subsection{Construction of teachers group}

The construction of teachers is the emphasis to implement bilingual teaching at present. Though most teachers possess profound subject bases, but lack the cross and integration of subjects, and the subject teachers could not comprehensively grasp English. But bilingual teaching requires that teachers must possess comprehensive series knowledge structure, profound English basic knowledge and communicative ability of hearing, speaking, reading and writing, and relative knowledge such as social culture, local conditions and customs, words concept and posture language, which can better avoid the misapprehension induced by cultural difference, and favorably utilize English to communicate. Bilingual teachers must be composite talents with multiple abilities, which require higher demands for teachers and future teachers.

\section{Applied example of circuit bilingual teaching}

Circuit is a c professional base course, and some Chinese colleges begin to explore the bilingual teaching to the circuit course in succession. Because of teaching materials, the bilingual teaching of circuit gives priority to Chinese teaching material and supplement by English materials.

Taking the circuit model and circuit law in the first chapter of "Circuit" edited by Qiu Guanyuan as an example, we would show how to develop Chinese-English bilingual teaching in the teaching of circuit course. To obtain better teaching effect, we should reform general teaching mode, for example, compiling the English-Chinese conversation or Chinese-English conversation of some glossaries in the circuit course, adopting the mode of small class school, increasing opportunities to communicate teacher with students or students with students by English, printing compiled PPT courseware for students before class and solve the problem giving attention to listen and note. According to students' English level, we generally adopt the transitional teaching mode in the initial teaching period.

In the first part, we narrate the basic knowledge and main objective of the circuit course, and because this part is shallow and unprofessional, we can use English to teach.

In the second part, we narrate the main contents of the first chapter including some apparatus composed by basic circuits and simple circuit analysis method. We can teach the introduction of apparatus in English. But to some circuit analysis methods, if we teach in English, some students with worse English base may hardly understand. English teaching would increase the understanding difficulty of professional knowledge. We should not influence the learning effect of professional course because of the use of bilingual teaching mode, and the arrangement of teaching process should make students better understand professional knowledge, so teachers should decide the difficult degree of knowledge according to teaching content. For profound professional theoretic knowledge, we should apply English to teach and should not blindly pursue the using quantity of foreign language. 
The part of Kirchhoff's Laws has strong specialty and the emphasis of professional lesson is the learning of professional knowledge, so we can not blindly teach in English, and the difficulty in the lesson should teach in Chinese to achieve better teaching intention.

\section{Conclusions}

In the article, we introduce the background and key factors for the bilingual teaching of circuit. In the undergraduate teaching, many problems still exist in the bilingual teaching of circuit course, and aiming at these problems, we should further study many aspects such as the construction of teaching material and teachers and the teaching method. The bilingual teaching of circuit has very important meaning to cultivate professional talents, and it is the task which should be studied for long.

\section{References}

De Saussure, F. (2001). Course in General Linguistics. Beijing: Foreign Teaching and Research Press.

Dong, Zhenwang. (2008). Teaching Outline for Circuit Analysis. [Online] Available: http://soe.jxufe.cn/old_dzxy/upfile/200610/2006102865529000.doc (May 15, 2008).

Chen, Xiao. (2008). On Design Experiment Teaching in Engineering Quality Cultivation. International Education Studies, 1(3): 49-51.

Gao, Yihong. (2000). The Cognition to the Language Culture Difference. Beijing: Foreign Language Teaching and Research Press. Aug, 2000.

He, Kekang. (2002). Education Technology Theory. Beijing: Beijing Normal University Press. Oct, 2002.

$\mathrm{Hu}$, Xiaochun. (2008). Practice and Research of Bilingual Teaching in the Undergraduate Course Education of Engineering Colleges. [Online] Available: http://www.btrc.edu.cn/main/jxyj/llyj/200610270002484.shtml (May 15, 2008).

Jiang, Hongde. (2008). Form and Transformation of Bilingual Teaching Research Result. [Online] Available: http://www.tesol.cn/yan_jiu/07_08_yan_jiu/jhd_hu_nan_jianghua.html (May 20, 2008).

Johnston, B. (1999). Theory and Research: Audience, Language Use, and Language Learning. In J. Egbert \& E, Hanson-Smith (Eds.), CALL Environments: Research, Practice, Practice and Critical Issues. Alexandria, Virginia: Teachers of English to Speakers of Other Languages, Inc. P.55-64.

Lado, R. (1957). Linguistics across Cultures. University of Michigan Press.

Qiu, Guanyuan. (1999). Circuit. Beijing: Higher Education Press. Jun, 1999.

Ron Belisie. (1996). Email Activities in the ESL Writing Class. The Internet TESL Journal. Oct, 1996.

Shu, Dingfang. (1996). Modern Foreign Language Teaching. Shanghai: Shanghai Foreign Language Audiovisual Press. Oct, 1996.

Wang, Binhua. (2003). Bilingual Education and Bilingual Teaching. Shanghai: Shanghai Education Press.

Zhang, Junbin. (2008). Study on College Chemistry Bilingual Teaching. [Online] Available: http://www.btrc.edu.cn/main/jxyj/llyj/200610270002483.shtml (May 17, 2008).

Zhang, Suqun. (2008). Thinking of China Bilingual Teaching. [Online] Available: http://www.btrc.edu.cn/main/jxyj/llyj/200610270002484.shtml (May 15, 2008).

Zhang, Zhengdong \& Huang, Taiquan. (1999). Bilingual Tutorial of English Teaching Method. Beijing: Sciences Press. Aug, 1999.

Zhao, Chengping \& Huangping. (2004). Breakthrough of Bilingual Teaching. Chongqing: Chongqing University Press. Aug, 2004. 